\title{
Supporting athlete success on and off the field
}

W

hen 27 college field hockey players filed into the Virginia Wesleyan College (VWC) library one summer afternoon, many for their first time, the librarians could hardly contain their enthusiasm. Partnering with the field hockey coaches was akin to getting picked by the cool kids' team at recess, and we were not going to let anyone down. We recognized that outreach to all campus communities is essential to remaining relevant in a dynamic environment, so what better way to kick off our efforts than to team up with our colleagues in Athletics. True, we may not be stunning specimens of speed and power (yet), but our experience taught us that coaches and librarians make an unbeatable team.

\section{In the huddle}

Creating SMART goals each year has enabled the VWC librarians to prioritize and manage the instructional and outreach activities necessary to support students' educational success. One of Patty Clark's 2014 performance goals included: schedule and meet with coaches/ assistant coaches from at least one team and provide information about library assistance to students and available resources. The library director talked with the director of athletics about this goal to make sure she was on board. The athletic director suggested starting with newly hired coaches, which led to a spring meeting with the new field hockey coach, Christina "Stivo" Restivo, and Assistant Coach Kellie Finn. While the meeting focused on library instruction, spaces, and resources, we all agreed that students need to develop the ability to recognize and use credible information for any type of research—what librarians recognize as informa- tion literacy habits. The coaches enthusiastically requested a preseason library workshop for the team, enabling students to start the fall semester and season with strong research skills.

In early August, Coach Stivo and Coach Kellie introduced the librarians to the concept of "prehab" or prehabilitation training. They wanted the students to learn specifically about injury prevention techniques and asked that we incorporate the library workshop into preseason training. Prehab training can potentially prevent field hockey injuries in four areas: quads, hamstrings, IT band, and the lower back. While kinesiology may not be part of VWC curriculum, understanding how the body works remains essential to athletic performance and health, and is the responsibility of each athlete. The library workshop would support the team in its training by teaching the skills to recognize credible sports therapy information, in effect, using transferable research skills to become stronger players and stronger students.

With prior approval of the library director, librarians suggested that an underutilized second floor corner of the library be designated as a field hockey team study location to further develop the relationship with the team. The coaches gave strong support to the idea. Newly hired Research Librarian Jenny Erdmann agreed to lead the research component of the workshop, offering the valuable perspective of someone new to VWC.

Jenny Erdmann is research librarian, email: jerdmann@ vwc.edu, and Patty H. Clark is research librarian and electronic resources coordinator, phclark@vwc.edu, at Virginia Wesleyan College's Hofheimer Library

๑ 2016 Jenny Erdmann and Patty H. Clark 


\section{Game day}

Starting the academic year with a group of enthusiastic coaches and players in the library was tremendous fun. At the beginning of the season, every player has a positive attitude and is eager to impress. The students were glad to take a break from outdoor training in the air helped with team building. The team's faculty advisor, an English professor, also participated in the session, reinforcing the academic support available to student athletes.

We also asked the students about their experiences with research and the library, giving the floor to the more experienced players to offer useful advice on

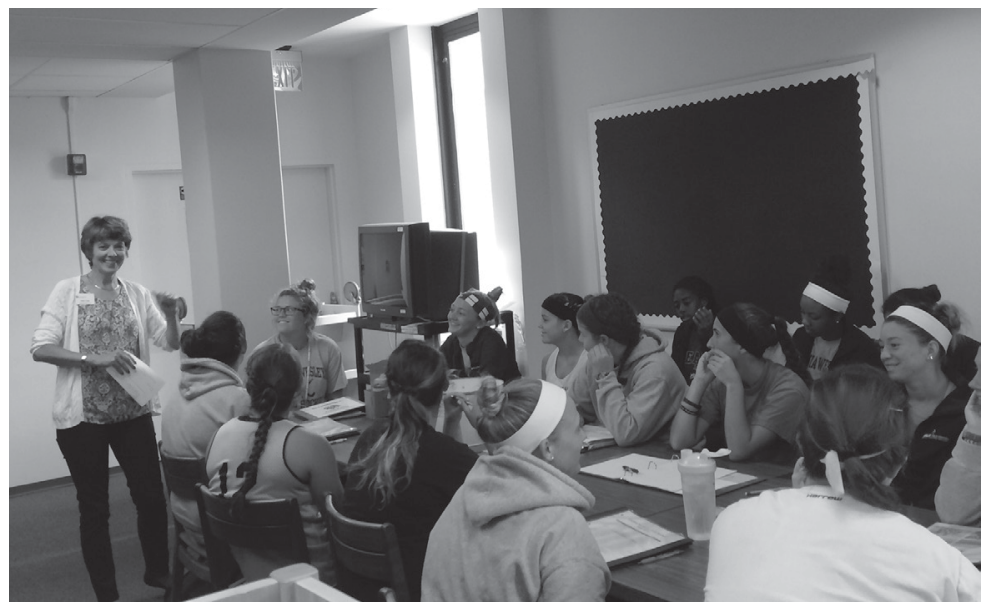

Patty Clark leading the discussion of favorite snacks, study skills, and study habits.

conditioned library and participated fully. There were even returning players that greeted Clark by name, asking about how her summer had been. The preseason workshop was an energizing start to the season.

First half: We met in the field hockey team's designated library study space and asked the students to identify some of the parallels between athletics and research. The students suggested knowing how to effectively use and take care of equipment, developing skills, needing to count on experts to provide help, and learning how to not waste time with mistakes or poor habits. Additional parallels between athletics and research that we had identified prior this session included the importance of understanding the rules and expectations, the need to practice to succeed at a higher level, and the consequences of cheating.

We included several activities as icebreakers to engage the students, including asking each student to identify her birthday, favorite snack, a personal strength or skill, and a "weak study habit." The coaches observed that sharing these and off the field. Our juniors and seniors had specific suggestions about reserving study rooms and time management.

Second half: Erdmann led the interactive information literacy workshop on injury prevention and evaluating information sources in the computer lab. She introduced the students to the ABCs of source evaluation (Authority, Bias, and Currency), a technique they would be hearing frequently in subsequent library sessions. The workshop was designed to facilitate group work, with each team researching appropriate prehab techniques. The four groups were seated together and given independent research time with their partners. Erdmann's worksheet helped students identify prior knowledge of their topic, key search terms, search strategies, and potential information sources.

Like all good teammates, the group members were able to support each other and reiterate the concepts discussed in the session as they searched for credible prehab resources.

\section{Team banquet}

That same week, we were invited to join the team for dinner and research presentations. Not only was this one of those rare opportunities to sit at the cool table, but Coach Stivo had told the students they would be competing for best presentation. Given that our competitive women athletes would go toe-to-toe for a stick of gum, we knew we were in for a treat. 
Expanding their research findings into group presentations enabled students to connect their research on prehab exercises to their training regimen. The students were expected to identify the part of the body involved, how the injury might occur during field hockey play, and appropriate exercises and training. The coaches, trainer, and librarians asked the students to discuss and defend their use of authoritative, nonbiased, and current sources. This assignment provided an opportunity for students to practice their oral presentation skills, one of their college graduation requirements.

Determined to win, each group employed creative visuals: a giant cookie with hamstrings highlighted in green icing, a large painting by an art major showing all the muscles and tendons, and body paint to show specific leg muscles. We cheered enthusiastically like embarrassing relatives at a field hockey match. The nature of reference librarianship means we often interact with students during times of confusion or difficulty, even frustration, so it was a gratifying experience to see them shine.

\section{An unbeatable team}

Our collaboration with the coaches from the early re- competition. search stage to the presentation stage established that librarians are a valuable resource for academic study and are invested in the players' success as students and as athletes. The more time librarians spend with the student athletes, the stronger this relationship becomes. The workshop also provided a valuable opportunity to demystify the research process, arm students with the skills to succeed at a particular task, and leverage individual talents in the process. Through hands-on practice, the students showcased their talents and built confidence in their ability to research successfully.
Creating a team study hall space was a problemsolver for both librarians and coaches alike. The field hockey team admirably enforces mandatory study hall, but finding a space on campus conducive to studying has been a challenge. The librarians, students, and coaches agreed that the isolated corner on the second floor would provide a distractionfree zone. Team members have become so comfortable in the space, that many choose to study there outside of regularly scheduled study hall hours. This is an encouraging sign that the players are comfortable within the library, a positive indicator of future use.

The library instruction program at VWC emphasizes transferrable skills that have utility beyond a particular course, and even beyond the classroom environment. The search techniques the field hockey students applied as

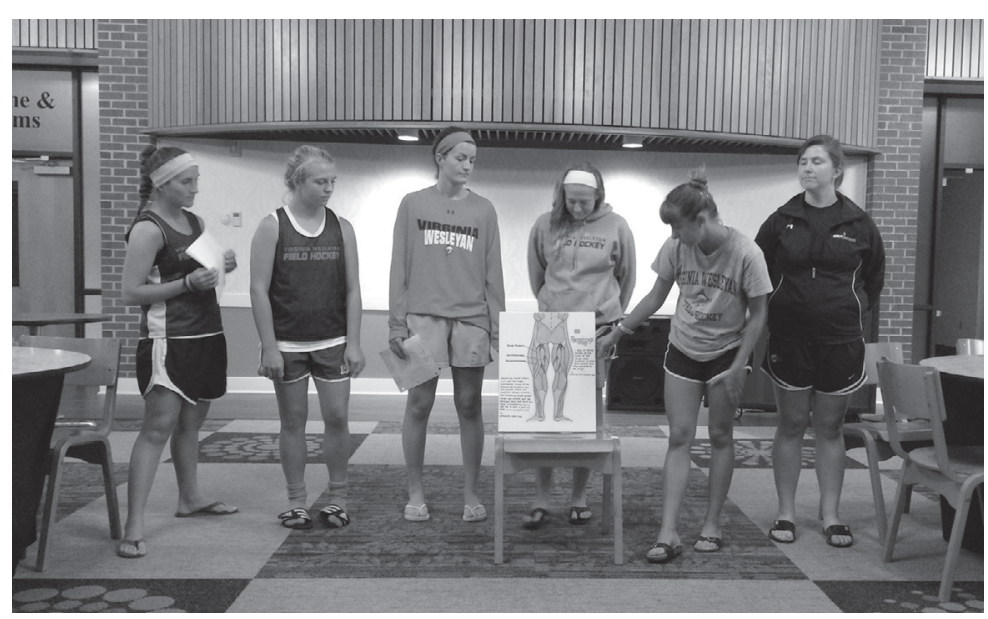

Field hockey player Caitlyn's artistic ability gave her group a "leg up" on the they researched prehabilitation exercises underscored how skills learned in the classroom can ultimately help them become better, healthier athletes.

\section{Recruiting and training for next season}

As this workshop took place prior to the start of the semester, we had time to reflect and consider what we might do differently the next time.

- Students' were confused by the vague directions for the injury prevention research assignment. Developing clearer assignment (continues on page 157) 
Community College (AACC) deployed a combination of indirect measures and authentic assessment of student work, using assessment tools flexible enough to be deployed across the college. The results of AACC's AiA project have provided college practitioners and stakeholders with evidence of the extent to which graduating students demonstrate crucial information literacy skills and with data that can inform decisions about how to foster more effective teaching and learning.

\section{Online Forum on Assessment in Action}

In conjunction with the release of the special issue, CERL will sponsor an online forum focused on the AiA work conducted at two of the institutions included in the collection: Anne Arundel Community College and Grinnell College. AiA participants from these institutions will describe their work as part of the project, how the data collected informed decision-making and practice at their schools, and the value that the AiA experience had for them (and their colleagues) in terms of professional development. The CERL Online Forum on Assessment in Action will be held on March 24 at 2 p.m. (CST). For information on how to register, please visit http://crl.acrl. org/site/misc/fora.xhtml.

\section{Online Forum on Student Success recording available}

The CERL Online Forum on Student Success, originally scheduled for October 28, 2015, is now available as a recording. The asynchronous session was recorded on January 6, 2016, thanks to the extraordinary efforts of CERL Social Media Editor Sarah K. Steiner and participants including Felly Chiteng Kot (Nazarbayev University) and Jennifer L. Jones (Georgia State University). For this and other recordings of past forum programs, please visit: http://crl.acrl.org /site/misc/fora.xhtml.

\section{Note}

1. Marie R. Kennedy and Kristine R. Brancolini, "Academic Librarian Research: A Survey of Attitudes, Involvement, and Perceived Capabilities," CERL 73 (2012): 431448, accessed January 21, 2016, doi: 10.5860 /crl-276. n

\section{("Librarians in the huddle," cont. from page 146)}

objectives would help develop student research confidence. Coaches would likely be very open to librarians developing specific research requirements.

- Rather than asking students to identify a "weak study habit," each student should identify one SMART academic goal for the semester. This would encourage individual accountability and help students see their progress and improvement.

- There could be value in each of the librarians working with players from different graduating classes: perhaps Clark working with freshmen and sophomores, and Erdmann working with juniors and seniors.

At the team dinner, the coaches confided to us that the majority of the students lacked confidence both as athletes and as students. This had been observed during our first session with the students when few were able to identify a personal strength or skill. The lack of confidence in our driven, toughminded female athletes was surprising but relevant to how we design future workshops and library instruction activities for all students.

This pilot project with the field hockey team led to discussing other opportunities for collaboration. In addition to working with faculty and the academic program, it is time to ask other college departments "What do you want the students to know?"

At VWC, we will be seeking collaboration with International Programs and Model United Nations as well as other sports teams. Librarians can develop activities, assignments, and discussions that enable more learning opportunities. Students can reap demonstrated benefits from information literacy skills outside the traditional classroom environment, and librarians will be there to cheer them on in every aspect of their undergraduate experience. $\boldsymbol{n}$ 